\title{
A Survey on the Order of Gendered Binomials and Attitudes towards Gendered Roles
}

\author{
Suthinee Promkandorn
}

\begin{abstract}
Even with rising concerns about gender equality in many countries, sexist languages appear to be very common in every day communication. Based on sociolinguistic perspectives, this study seeks to investigate if a male or female term is addressed first in personal binomials and to explore the attitudes towards gender roles. The participants included 20 international students from a Thai university. The data was collected by using a questionnaire which consisted of two sections. The first section asked the participants about the order of common gendered binomials they used in their language. The second section questioned which gender (i.e. male, female, or both) was more appropriate towards particular roles in the society, including family roles, social roles, and political roles. The findings indicated that most of the subjects conventionally addressed male terms first, with a percentage of 67.42. Male-Female binomials were higher among the Asian subjects than the Western ones, and among males more than females. Regarding attitudes towards gender roles, the participants thought that "both genders" were equal to most roles $(41.67 \%)$, followed by male (33.96\%) and female (24.38\%). Among Asian participants, the opinions towards male roles were apparently strong, especially in male Asians. Contrastively, gender equality was perceived very important among Westerners, particularly in females. Accordingly, the study concluded that attitudes towards gender roles were an important factor underlying the linguistic patterns of gendered binomials.
\end{abstract}

Index Terms-Binomials, language and gender, sexism, sexist language, word order.

\section{INTRODUCTION}

Sexism involves behaviour which maintains social inequalities between women and men. The term 'sexism' is defined as "discrimination within a social system on the basis of sexual membership' [1]. In many cases, the bias is in favour of men against women [2]. Sexism is reflected in a language as well, both structurally and verbally. For example, the use of English gendered title "Mr vs. Mrs" that clearly distinguishes marital status of men and women or a generic pronoun "he" to cover both sexes. This gender-biased language, occurring consciously or subconsciously, is influenced by the cultural norms and the societies we are in. Our expectations towards gender roles are different based on the society's values and beliefs. Ones might expect men to be breadwinners, or women to be housewives and so on. However, one thing is clear -- in

Manuscript received December 1, 2017; revised February 7, 2018. This work was supported in part by the English Department, Faculty of Humanities and Social Sciences, Payap University.

Suthinee Promkandorn is with the English Department, Faculty of Humanities and Social Science, Payap University, Thailand (e-mail: p.suthinee@hotmail.com). almost every society, men are traditionally stereotyped as strong, smart, and powerful, while women, on the other hand, are seen as weak, modest, and dependent.

This view has never been changed even with today's feminist movements and the recognition of the equality between men and women. There are still pervasive examples of sexism in everyday language [3]. According to Mills [4] sexism in language could be analyzed at three levels: word-level, sentence-level, and discourse-level. This paper seeks to investigate sexism at word level through the order of gendered noun phrases which are conjunct - for example, one might say 'dad and mom', whereas others might use 'mom and dad', and to explore people's attitudes towards gender roles, which could be an important factor of the gendered order.

\section{LITERATURE REVIEW}

Mooney \& Evans [3] states that there is a strong tie between language and gender. Gender is a social term which is usually confused with the term 'sex'. It is a socially constructed concept, referring to values, meanings, and characteristics of human beings through their interactions and environments [5]. Sex, on the other hand, is a biological and physiological category which are referred to the differences between women and men [6].

One of the most discussed topics among language and gender issue in sociolinguistics is a sexist language. Sexist language is a gender bias particularly against females. People tend to assume that man is the norm and woman the 'other' [7]. Mooney and Evans [3] listed certain areas where gender bias at lexical level becomes apparent including:

\section{A. Marked Term}

The word actor, for example, is an 'unmarked' term because it refers to a male and actors in general. 'Actress', however, refers only to a female actor. Different forms indicating only a female one is considered 'marked'. In the context of gender, we find that terms referring to men are generally unmarked and considered neutral while those referring to women are marked for sex. Similar examples are prince/princess, waiter/waitress, host/ hostess and so on. Another technique used to indicate female is using a clear word, for example, woman, lady, female, or girl to represent by combination with the occupational word. For example, a lady doctor, a female attendant, and a girl reporter [8].

\section{B. Generic Man}

In many cases, it was found that a male term is not really sexed, but rather is generic and refers to both sexes. The word 
'man' has become very ambiguous between the generic and the masculine meaning [2]. For example, in a sentence such as Man loves to hunt, people may not be sure whether women are included or not. It is also clear that the word man is associated with male images, even when it is used in a generic sense. Hudson [9] provided an example of the word 'doctor' which is not specified by sex. Although the term is usually referred to both sexes, we more usually identify it as a male than female. It is the same situation in most other professions' names.

\section{Semantic Derogation}

Gender inequality can be seen in a term of semantic derogation when a word comes to have negative meanings overtime. There is a high number of images compared to women in negative ways. For instance, bitch, old biddy, and cow are compared to women contrasting with stud and wolf which are compared to men [2]. We can see that a lot of terms referring to men usually convey positive images, while there is a negative connotation related to women.

\section{Methodology}

\section{A. Instruments}

This study uses a survey questionnaire to collect the data. The questionnaire consists of two parts. The first part asks the subjects to choose whether they address a male or female term first in their language with given pairs of gendered binomials. Following Motschenbacher [10], the study lists gendered nouns in seven categories including general nouns, address terms, nobilities titles, heterosexual roles, kinship terms, occupations, and pronouns.

\begin{tabular}{ccc}
\multicolumn{2}{c}{ TABLE I: EXAMPLES OF GENDERED NOUNS IN PERSONAL BINOMIALS } \\
\hline \hline Binomial types & Male & Female \\
\hline General nouns & Man & Woman \\
& Boy & Girl \\
Address terms & Gentleman & Lady \\
& Sir & Madam \\
Nobilities titles & King & Queen \\
& Prince & Princess \\
Heterosexual roles & Husband & Wife \\
& Groom & Bride \\
Kinship terms & Father & Mother \\
& Aunt & Uncle \\
Occupations & Actor & Actress \\
& Host & Hostess \\
Pronouns & He & She \\
& Him & Her \\
\hline \hline
\end{tabular}

The second part focuses on attitudes towards gender roles in society, namely family roles, social roles, and political roles. The subjects responded to the questionnaire regarding which gender they think was more appropriate towards particular roles in their country. For example, "Who should be responsible for financial issues in a family?” was listed under family roles, "Who do you prefer as a boss?" under social roles, "Who should be a political leader?" under political roles, and so on.

\section{B. Data Collection and Analysis}

The subjects were chosen using a purposive sampling method. In order to find out what gendered order of languages from different parts of the world is, the questionnaire was administered and distributed to 20 international students, from Asian and Western countries with an equal number from both genders. They were asked to complete the questionnaire and provided additional comments regarding male/female roles. The order of Male-Female binomials were then calculated into percentage using descriptive statistics in an Excel spreadsheet. The subjects' attitudes towards gender roles were analyzed and compared with the use of gendered binomials.

\section{FINDINGS}

\section{A. The Order of Gendered Binomials}

The figure below presents the findings of the order of gendered binomials from the first part of the questionnaire. The findings indicated that the subjects widely addressed male terms first in binomials (67.42\%), while Female-Male binomials were approximately one-third of the total items.

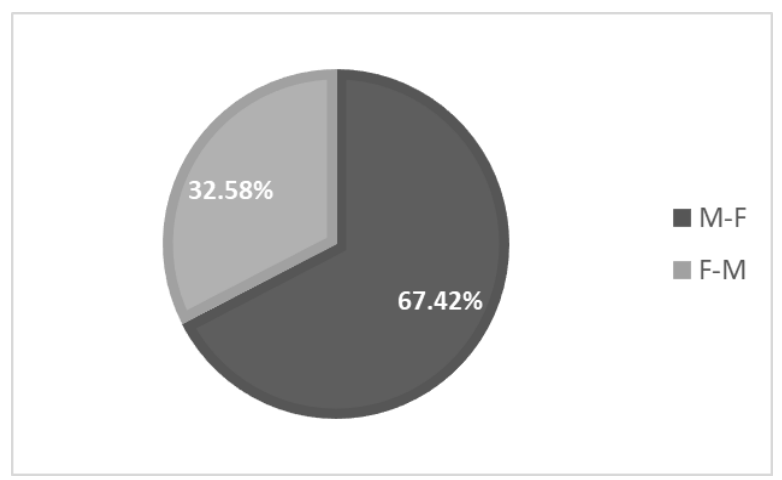

Fig. 1. Gendered binomials ordering.

Among these terms, Nobilities titles received the highest percentage with over 80 per cent, and closely followed by Occupations. This suggested that the terms such as King-Queen or Actor-Actress were commonly used throughout every culture. In addition, other terms i.e. pronouns, heterosexual roles, address terms, and general nouns were mostly ordered as Male-Female. These evidences, as a result, indicated that men were traditionally presumed a leader role, and women a follower.

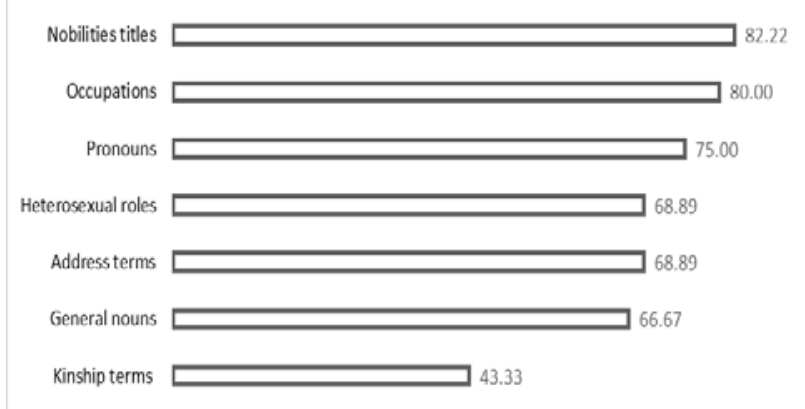

Fig. 2. Male-Female binomials categorized by terms. 
In contrast, the only domain where a female term was addressed first more than male was Kinship terms, such as Mother-Father or Aunt-Uncle. These instances signified that there might be certain fields in which women are dominant, and these fields are considered feminine, such as the roles of parenting and siblings.

When categorizing into nationalities (Asian Vs. Western), Asian participants used M-F a little higher than Western participants, but the distinction was not obvious.

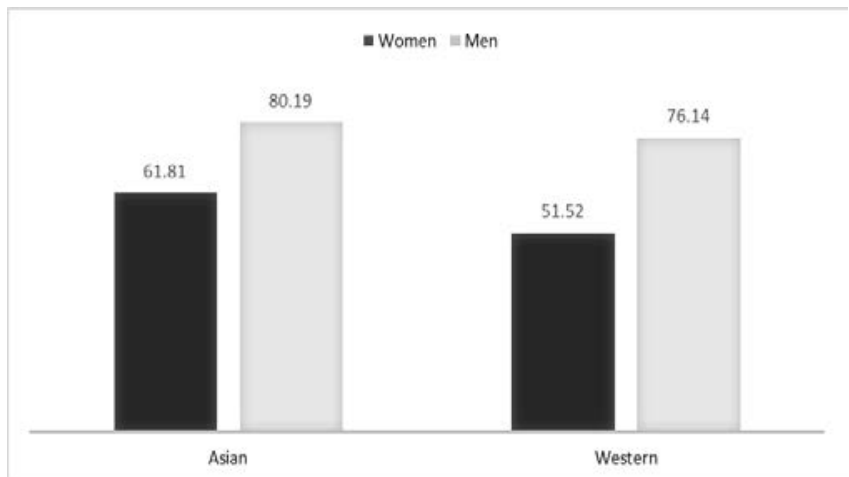

Fig. 3. Male-Female binomials by nationalities and genders.

This distinction, however, was greatly observed among different genders. We can see from Fig. 3 that men from both nationalities significantly addressed male terms first more than women. However, an outstanding figure was found among western women. Surprisingly, the chart revealed that -unlike people from other groups -- western women almost equally ordered M-F (51.52\%) and F-M (48.48\%).

\section{B. Gender Roles}

Fig. 4 illustrates the percentage of gender which was thought to be more suitable towards particular roles in the society. It was found that the subjects selected "both genders" the most. This means that people have come to realization of gender equality in many parts of the world. Unlike traditional views on sexes where women were dependent on men, the study reflects people's perspectives that women and men hold similar roles in the society. However, men were still perceived to hold more responsibilities in the society than women.

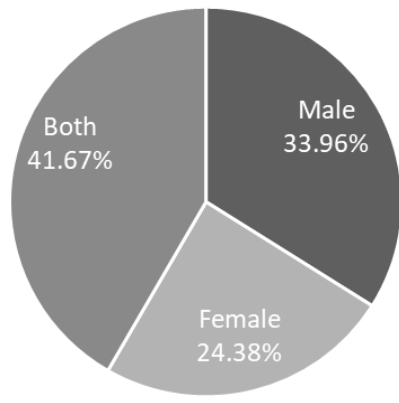

Fig. 4. Attitudes towards gender roles.

Nevertheless, when we look closely into each nationality and gender, we can see that there are some interesting issues here. Table II demonstrates that the people from all groups thought that 'both genders' were suitable with many roles, except Asian men. The majority of them still conformed to the conventional perspectives in which men are dominant in the society. This is, however, in contrast with Western women, where over a half argued that both men and women were equal towards gender roles.

TABLE II: ATTITUDES TOWARDS GENDER ROLES BY NATIONALITIES AND GENDERS

\begin{tabular}{lccccc}
\hline & \multicolumn{2}{c}{ Asian } & \multicolumn{2}{c}{ Western } & \\
& Women & Men & Women & Men & Average \\
\hline Male & 35.17 & $\mathbf{4 5 . 8 3}$ & 20.50 & 34.33 & 33.96 \\
Female & 26.00 & 18.83 & 25.83 & 26.83 & 24.38 \\
Both & 38.83 & 35.33 & $\mathbf{5 3 . 6 7}$ & 38.83 & 41.67 \\
\hline \hline
\end{tabular}

The findings from this study reveal a striking pattern about the relationship between language and gender. Referring to Fig. 3, the highest percentage of M-F binomials was found among Asian men (80.19\%), and the lowest among Western women (51.52\%). In the same way, the numbers from Table II show that people's attitudes towards gender roles are different. In Asian society, men are considered more powerful than women and it is evident among Asian men who supported that most leading roles belong to men (45.83\%). On the contrary, in Western perspectives, gender equality is stronger, particularly among women who thought that both genders held similar roles in the society (53.67\%). Accordingly, we can conclude from the findings that attitudes towards gender roles influence how people order words in gendered binomials.

\section{CONCLUSION}

In the modern world, even with the recognition of gender equality, sexist language is still everywhere. One of the sexist languages this paper is trying to examine is the order of gender terms in noun phrases. It is not surprising that a male term is often addressed first in most cases. Social beliefs and expectation well reflect how language is exercised. Nobilities, for instance, are where we would expect the image of a king rather than a queen. Occupations, e.g. doctor, actor are also where male images often pop up first. Therefore, the conventional Male-Female ordering in binomials may be the indication of women's lesser power in the social hierarchy. On the other hand, in a family domain where we often perceive women as those who take the roles of parenting, the Female-Male binomials are used, of course not by chance. The study found that such orderings coil with how people perceive gender images in the society. People with conventional perspectives of male dominance tend to use more $\mathrm{M}-\mathrm{F}$ orderings. In contrast, those with strong attitudes towards gender equality are likely to use less M-F orderings. Therefore, it can be concluded that social values and beliefs as well as attitudes are the factors underlying linguistic patterns, at least in the orderings of personal binomials in many languages.

\section{REFERENCES}

[1] R. Wodak, Critical Discourse Analysis, London: Sage, 1997, pp. 258-284.

[2] J. Holmes, Introduction to Sociolinguistics, 4th ed. NY: Routledge, 2013. 
[3] A. Mooney and B. Evans, Language, Society, and Power, 4th ed. NY: Routledge, 2015.

[4] S. Mills, Language and Sexism, Cambridge: Cambridge University Press, 2003.

[5] A. Blackstone, “Gender roles and society,” Human Ecology, CA: Santa Barbara, pp. 335-338, 2003.

[6] P. Simpson and A. Mayr, Language and Power, NY: Routledge, 2010.

[7] D. T. Ngoc. (December 2013). Understanding the relationship between language and gender. Gender and Society Research Center, Hoasen University. [Online]. Available: http://gas.hoasen.edu.vn/en/gas-page/ understanding-relationship-between-language-and-gender

[8] K. Víšková, "Language in the press: Gender bias on lexical level in broadsheets and tabloids,” M.A. thesis, Department of English and American Studies, University of Pardubice, 2006.

[9] R. A. Hudson, Sociolinguistics, Cambridge: Cambridge University Press, 1996.
[10] H. Motschenbacher, "Gentlemen before ladies? A corpus-based study of conjunct order in personal binomials," Journal of English Linguistics vol. 41, no. 3, pp. 212-42, 2013.

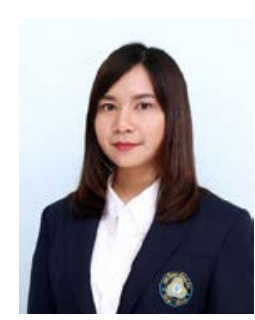

Suthinee Promkandorn is currently a lecturer and researcher at English Department, Payap University, in Chiang Mai, Thailand. She has a demonstrated history of working in the higher education industry and a strong education professional with a master of Arts (M.A.) focused in linguistics from Payap University and a bachelor of arts (B.A.) in English from Chiang Mai University (first honors). Her primary research interests are on sociolinguistics, language and gender, language development, and the impact of globalization on local languages. 